\title{
Development of a Thermoelectric Cooling System for a High Efficiency BIPV Module
}

\author{
Jung-Sik Choi*, Jae-Sub Ko*, and Dong-Hwa Chung ${ }^{\dagger}$ \\ ${ }^{\dagger *}$ Dept. of Electrical Control Eng., Sunchon National University, Korea
}

\begin{abstract}
This paper proposes a cooling system using thermoelectric elements for improving the output of building integrated photovoltaic (BIPV) modules. The temperature characteristics that improve the output of a BIPV system have rarely been studied up to now but some researchers have proposed a method using a ventilator. The efficiency of a ventilator depends mainly on the weather such as wind, irradiation etc. Because this cooling system is so sensitive to the velocity of the wind, it is unable to operate in the nominal operating cell temperature (NOCT) or the standard test condition (STC) which allow it to generate the maximum output. This paper proposes a cooling system using thermoelectric elements to solve such problems. The temperature control of thermoelectric elements can be controlled independently in an outdoor environment because it is performed by a micro-controller. In addition, it can be operated around the NOCT or the STC through an algorithm for temperature control. Therefore, the output of the system is increased and the efficiency is raised. This paper proves the validity of the proposed method by comparing the data obtained through experiments on the cooling systems of BIPV modules using a ventilator and thermoelectric elements.
\end{abstract}

Key Words: BIPV, Cooling system, Efficiency, NOCT, STC, Thermal control, Thermoelectric element

\section{INTRODUCTION}

Recently, the necessity for research on alternative energy has increased due to limited amount of fossil fuel and environment pollution. Solar energy with its clean and noiselessness energy has received a great deal of attention. Conventional standalone PV systems and BIPV systems that do not required separate area are a useful technology in terms of economic considerations [1]. BIPV systems should be considered when attempting to design an efficient building. When PV modules are combined with building materials, they cause problems due to module temperature. BIPV systems have a problem with increased module temperature more than general PV systems due to the solar heat and thermal conduction of the surface of a wall because it is adhered to the building itself. This is a serous problem because an increase in PV module temperature causes a decrease in the performance of PV systems with crystalline silicon cells. Generally, module temperature decreases efficiency by about $0.5 \%$ for every $1{ }^{\circ} \mathrm{C}$ of temperature increase [2]. Research on module temperature measurement is required for high efficiency in BIPV systems.

Thermoelectric elements that directly convert heat into electrical energy or electrical energy into heat are applied in the energy, electrical and electron industries as thermoelectric generation and thermoelectric cooling devices [3]. A thermoelectric element which uses the Peltier effect has advantages such as eco-friendliness, simple structure, high reliability and

Manuscript received Dec. 7, 2009; revised Jan. 26, 2010

† Corresponding Author: hwa777@ scnu.ac.kr

Tel: +82-61-750-3543, Fax: +82-61-752-1103, Sunchon Nat'1 Univ.

* Dept. of Electrical Control Eng., Sunchon National University, Korea noiselessness. As a result, the thermoelectric cooling method is often applied to the cooling of IC manufactures and electronic machines of various kinds such as infrared ray sensors and laser diodes. It is also used for the focal plate cooling of charge-coupled device (CCD) elements for the miniaturization of electron parts, high electrification, and high density implementation in advanced countries. In addition, its use has expanded to applications in the consumer electronics industry such as refrigerators, air conditioners and heat exchangers as well as scientific measurement and medical equipment.

Therefore, this paper proposes a high efficiency BIPV system that uses thermoelectric elements to cool the temperature of the module. The PV module temperature is operated around the nominal operating cell temperature (NOCT) or the standard test condition (STC). In addition, this method minimizes power loss by maintaining a constant module temperature. The validity of the proposed cooling method has been proved through experimentation.

\section{Modeling OF the System}

\section{A. Modeling of the solar cell}

Fig. 1 shows the equivalent circuit of a solar cell where the short current $I_{s c}$ is equal to the photo-current $I_{c}$. The open voltage of the solar cell is decided by the diode saturation current $I_{o}$ and is expressed as follows[4][5]:

$$
V_{o c}=\frac{k T}{q} \ln \left[\frac{I_{c}}{I_{o}}+1\right]
$$




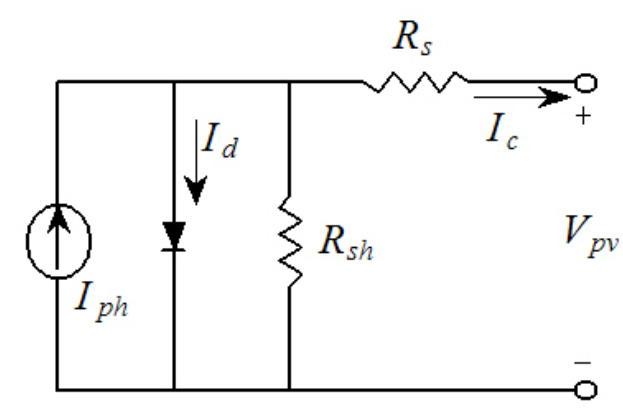

Fig. 1. Equivalent circuit of PV array.

where $V_{o c}$ is the open voltage, $k$ is the Boltzmann constant, $q$ is the electric charge, $I_{O}$ is the diode saturation current and $T$ is the operating temperature of the solar cell. In addition, a related equation for the short current and open voltage is expressed as follows:

$$
I_{s c}=I_{o}\left[e^{\left(\frac{q V_{o c}}{k T}\right)}\right] .
$$

The PV module is connected to a number of solar cells in series and parallel to get the desired voltage and current. In addition, the PV array is connected to a number of PV modules. An equation to obtain the current-voltage characteristic curve of the solar cell is expressed as follows:

$$
\begin{aligned}
& I_{p h}=I_{s c} S_{N}+I_{t}\left(T_{c}-T_{r}\right) \\
& I_{d}=I_{o}\left[e^{\frac{q\left(V_{p v}+I_{c} R_{s}\right)}{A k T}}-1\right] \\
& I_{o}=I_{o r}\left[\frac{T_{c}}{T_{r}}\right]^{3} e^{\frac{q E g}{B k}\left(\frac{1}{T_{r}}-\frac{1}{T_{c}}\right)} \\
& I_{c}=I_{p h}-I_{d}-\frac{V_{p v}+I_{c} R_{s}}{R_{s h}}
\end{aligned}
$$

where $I_{p h}$ is the Photo-current, $S_{N}$ is the radiation per area, $I_{t}$ is the short current temperature coefficient, $I_{d}$ is the diode current, $R_{s}$ is the series resistance, $R_{s h}$ is the parallel resistance, $T_{c}$ is the temperature of solar cell $[K], T_{r}$ is the command temperature of the solar cell $[K], A, B$ are the manufacture constants, $I_{o r}$ is the reverse saturation current and $E_{g}$ is the energy band gap. Fig. 2 shows a PSIM model of a PV array and it is able to calculate the theoretical maximum power point of PV generation through a PSIM simulation.

\section{B. Modeling of the thermoelectric element}

If a positive direct DC current flows to the n-type element in Fig. 3, the electrons move from the p-type to the n-type and the cold side temperature drops because the heat is absorbed. The absorbed heat is moved to the hot side of the module and emitted from a heat sink. At this time, the absorption and emission of heat is in proportion to the current and the coefficient of the thermoelectric element couple. Generally, $Q_{c}$ , which is emitted for a unit of time by the Peltier effect, is in proportion to the magnitude of the current, but is limited in accordance with the kind and type of thermoelectric element. If the temperature variations of the module ends are minimum, the maximum absorption values are calculated and a current larger than $I_{\max }$ decreases the absorption value.

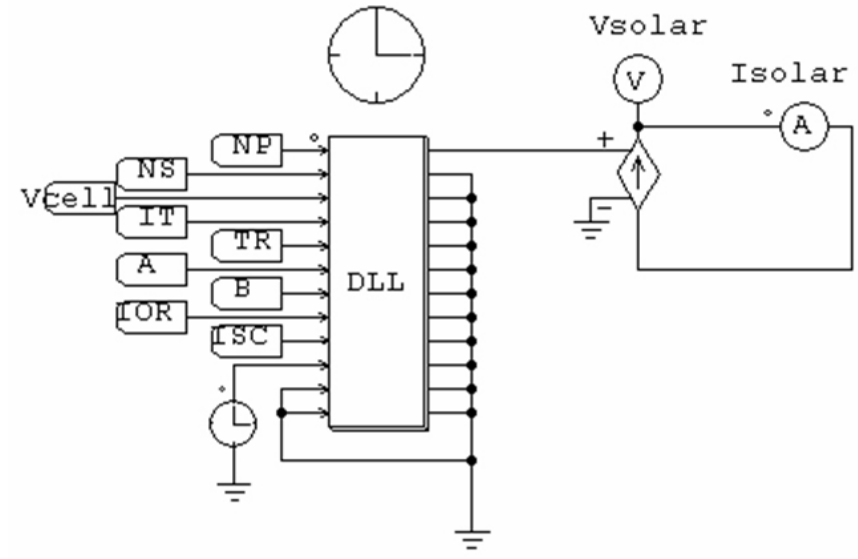

Fig. 2. PSIM model of solar cell array.

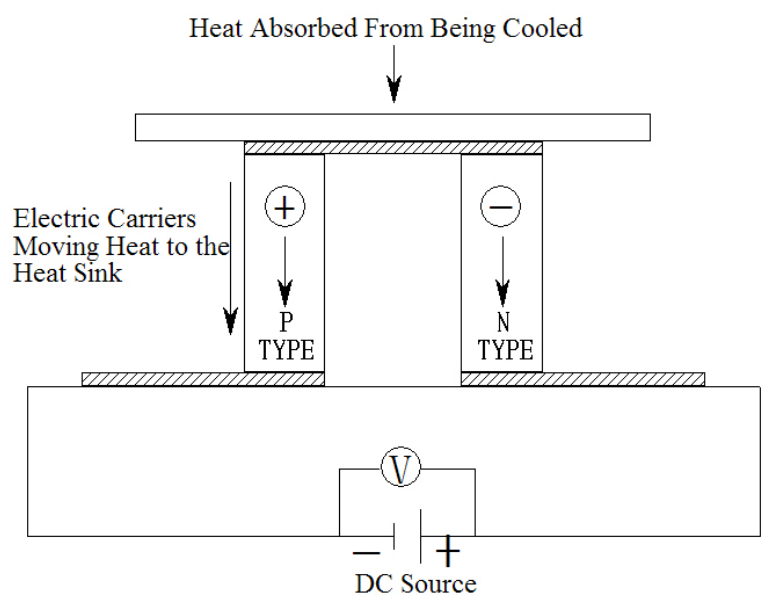

Fig. 3. Electrical connection of general single module.

The following equations express the relationship between the heat absorption value $Q_{c}$, the caloric value $Q_{h}$ and the consumption power $P[6]$.

$$
\begin{aligned}
& Q_{c}=\alpha_{e} I T_{c}-\frac{I^{2} R_{e}}{2}-K_{e}\left(T_{h}-T_{c}\right) \\
& Q_{h}=\alpha_{e} I T_{h}-\frac{I^{2} R_{e}}{2}-K_{e}\left(T_{h}-T_{c}\right) \\
& P=Q_{h}-Q_{c}=\alpha_{e} I\left(T_{h}-T_{c}\right)+I^{2} R_{e} .
\end{aligned}
$$

The state equation below expresses the relationship between the input source of the thermoelectric element and variations in temperature.

$$
\dot{T}=-K(T-u)
$$

where $\mathrm{K}$ is calculated by an experimental method that measured the reaching time from initial value to a steady state value of 63 percent and then took the reciprocal number when the step-input voltage was input to the thermoelectric element model.

The transfer function related to the real input and output of the thermoelectric element is expressed as follows: 


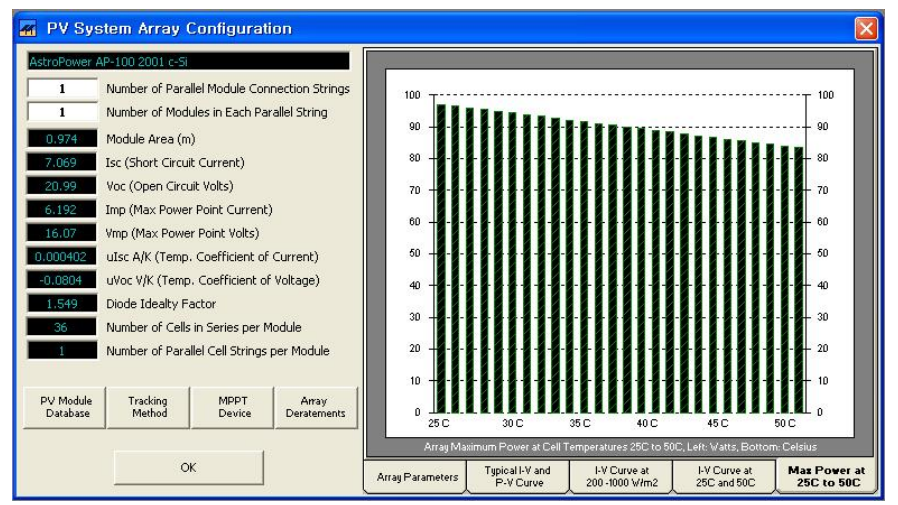

Fig. 4. Change power with PV module temperature.

$$
G_{T}(s)=\frac{K}{s+K}
$$

\section{Construction of the Control System}

\section{A. Temperature characteristic analysis of a BIPV module}

The electrical performance of a PV module is changed by incidence irradiation and the temperature of the PV module. When the temperature of a PV module's front panel and rear panel is raised by incidence irradiation in the PV module, the electric generation capacity is reduced because the performance of the solar cell drops. In the case of BIPV, the temperature of a module is greatly increased by the conduction heat of a building structure with incidence irradiation in the summer season.

The Design Pro program is able to simulate the generation value of a PV module with temperature variations. Fig. 4 shows the variation in $\mathrm{PV}$ generation with respect to changing temperatures around the module. The generation value decreases when the temperature rises by $1^{\circ} \mathrm{C}$ from the command temperature $25^{\circ} \mathrm{C}$.

PV generation is decreased by $15 \%$ when module temperature is $50^{\circ} \mathrm{C}$ rather than $25^{\circ} \mathrm{C}$.

In addition, the temperature characteristic analysis of a PV module has an effect on inverter selection for the PV generation equipment. If the PV module temperature rises, PV module generation efficiency is decreased, and if the PV module temperature is decreased excessively, the inverter will not operated in the range of maximum power because the open voltage $V_{o c}$ is out of the maximum power point tracking range.

\section{B. Temperature control using a PI controller}

Fig. 5 shows a PI controller for thermoelectric element control.

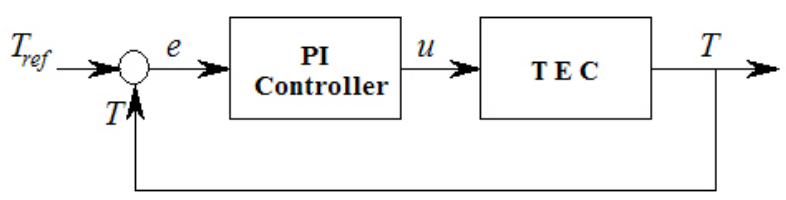

Fig. 5. Block diagram of PI controller. where $T_{\text {ref }}$ is the input temperature (nominal operating cell temperature or standard test condition), $T$ is the output temperature of the real module and $e$ is the error value of the input temperature and the temperature of the real module. If the transfer function of the thermoelectric element is $G_{T}(s)$ and the transfer function of the PI controller is $G_{P}(s)$, the transfer function of the close-loop system is expressed as follows:

$$
\begin{aligned}
\left.G_{(} s\right)=\frac{T}{T_{\text {ref }}} & =\frac{G_{T}(s) G_{P}(s)}{1+G_{T}(s) G_{P}(s)} \\
& =\frac{K\left(k_{p} s+k_{i}\right)}{s^{2}+K\left(1+k_{p}\right) s+K k_{i}}
\end{aligned}
$$

where $k_{p}$ is the proportion gain and $k_{i}$ is the integral gain.

Consequently, the control input $u$ is calculated using the transfer function of the thermoelectric element $G_{T}(s)$ and the transfer function of the PI controller $G_{P}(s)$. This is expressed as follows:

$$
u(t)=k_{p}\left\{T_{\text {ref }}(t)-T(t)\right\}+k_{i} \int_{0}^{t}\left\{T_{\text {ref }}(\tau)-T(\tau)\right\} d \tau
$$

\section{Design of the control algorithm}

The estimation of the module operating temperature can be done with a variety of methods but the NOCT or the STC methods are typical models [7][8]. When a BIPV experiences a rise in module temperature of $20 \sim-40^{\circ} \mathrm{C}$ then the temperature of the cell rises and the generation efficiency decreases. This happens because the electrical resistance is raised by high temperatures within the flow of electrons. Consequently, a cooling device for a PV module rear panel is needed to keep the module performance within the BIPV system designs [9].

Fig. 6 expresses the control algorithm for the proposed BIPV cooling system. First, the module rear temperature of the BIPV and the outside temperature are sensed using a data acquisition (DAQ) board. The sensed data is compare to the set value (NOCT is $45.5^{\circ} \mathrm{C}$, STC is $20^{\circ} \mathrm{C}$ ) of the program and if the module temperature is higher than the set value, the voltage is inputted to the thermoelectric element and the cooling system is operated. If the outside temperature is higher than $25^{\circ} \mathrm{C}$, the control mode is NOCT and if outside temperature is lower than $25^{\circ} \mathrm{C}$, the control mode is STC. Also, if the module temperature is lower than the set value, the voltage is cut and the BIPV system is operated in the general mode. With this, the PV module is operated around the control value during days when irradiation is very high and the power of the PV module is able to improve.

Fig. 7 shows the composition of the BIPV cooling system using thermoelectric elements. This system is composed of an irradiation meter, a module thermal meter, an air thermal meter and a thermoelectric element attached to the rear of the PV module. A micro-controller (Atmega128) is used to control the module temperature to maintain a nominal operating cell temperature. In addition, the monitoring system uses a DAQ board (60164U of National Instrument (NI) company) to measure the real-time temperature data. 


\section{EXPERIMENT AND RESULTS}

Table I displays the PV module specification for the experimentation in this paper. The module used is an ASE-160-GTFT/MC from SCHOTT solar company.

TABLE I

PV MODULE SPECIFICATION

\begin{tabular}{|c|c|}
\hline ITEM & SPEC \\
\hline \hline Rated Power & $160 \mathrm{Wp}$ \\
\hline Maximum Voltage & $36.9 \mathrm{~V}$ \\
\hline Maximum Current & $4.46 \mathrm{~A}$ \\
\hline Open Voltage & $43.5 \mathrm{~V}$ \\
\hline Short Current & $5.12 \mathrm{~A}$ \\
\hline Operating Temperature & $-40^{\circ} \mathrm{C} \sim+90^{\circ} \mathrm{C}$ \\
\hline NOCT & $45.5^{\circ} \mathrm{C}$ \\
\hline
\end{tabular}

Fig. 8 shows the proposed experiment set for verifying the results of this paper. First, we designed the two sets so that one is a BIPV module applied to a thermoelectric element and the other is a BIPV module applied to a ventilator to compare the performance. In addition, the BIPV module applied to the ventilator is able to cut the wind so that the temperature characteristics of a general BIPV module are available to analyze and measure the comparison data. The temperature control algorithm is implemented through the RS232 communication of a PC and control board, and realtime data on the PV module temperature, air temperature and irradiation are monitored through the DAQ board.

Fig. 9 shows a module temperature comparison of the cooling methods when the control mode is STC and the radiation is low level. The results show that the average module temperature of a BIPV system using a thermoelectric element is $24.48\left[{ }^{\circ} \mathrm{C}\right]$ and that the average module temperature of a BIPV system using a ventilator is $33.31\left[{ }^{\circ} \mathrm{C}\right]$. Fig. 10 and Fig 11 show a comparison of the module generating value and the accumulating generation value based on the cooling method.

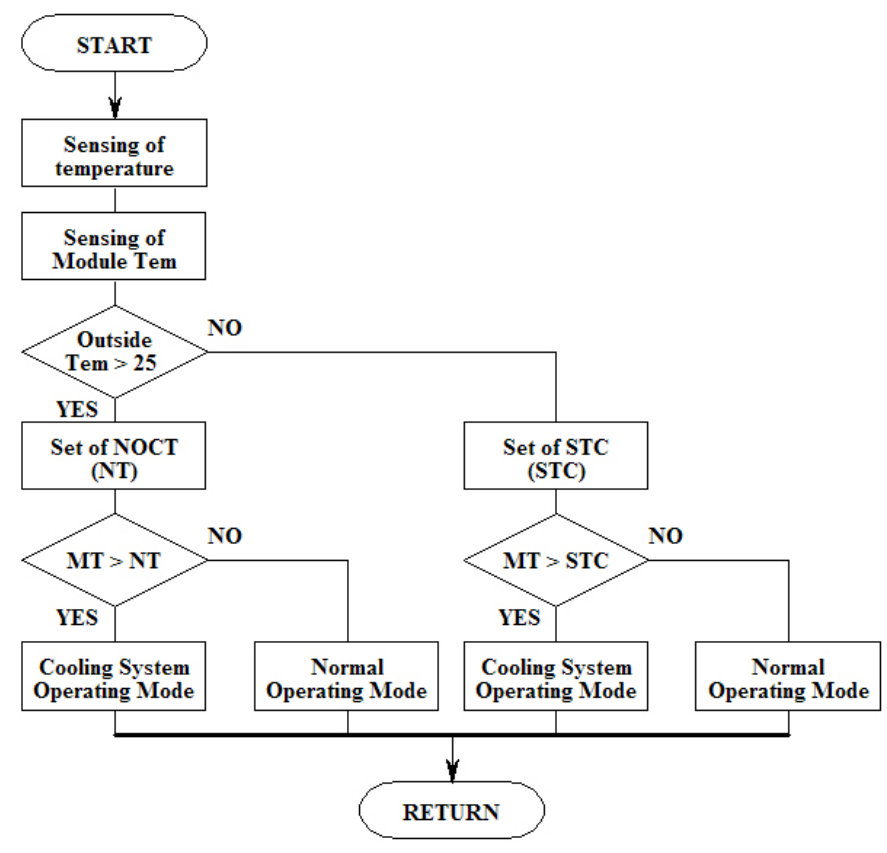

Fig. 6. Control algorithm of BIPV cooling system.

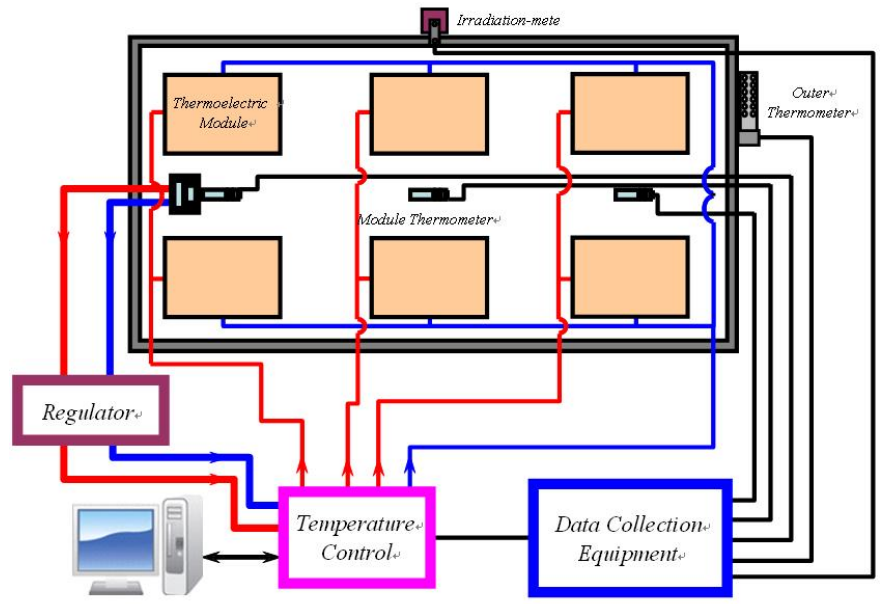

Fig. 7. Configuration of BIPV cooling system.

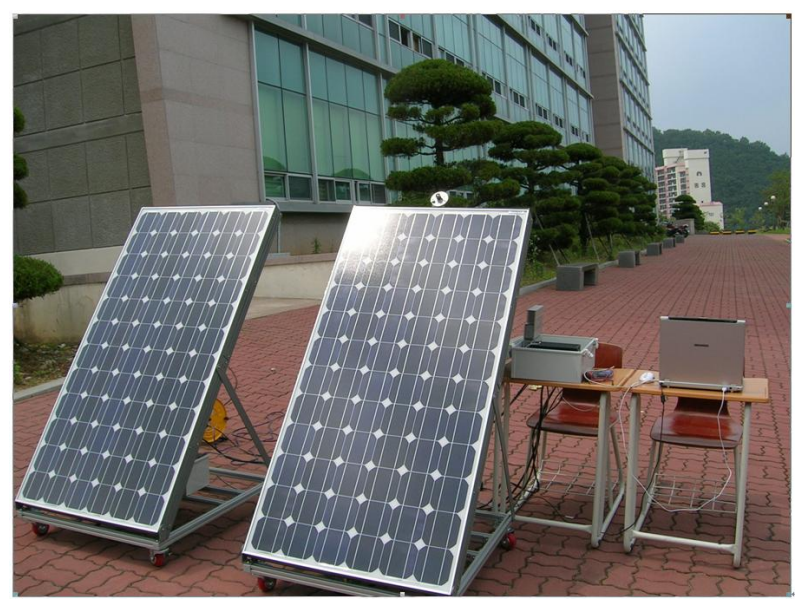

Fig. 8. Cooling experiment equipment of BIPV.

The generation value when using the thermoelectric element is higher 294.62[W] than when using the ventilator.

Fig. 12 shows a module temperature comparison of the cooling methods when the radiation is rapidly changed. The results show that the average module temperature of the BIPV system using a thermoelectric element is $25.35\left[{ }^{\circ} \mathrm{C}\right]$ and that the average module temperature of the BIPV system using a ventilator is $30.8\left[{ }^{\circ} \mathrm{C}\right]$. Fig. 13 and Fig 14 show a comparison of the module generating value and accumulating generation value based on the cooling method. The generation value when using the thermoelectric element is higher, 251.35[W], than when using the ventilator. When the control mode is STC, the efficiency of the PV module is high because the temperature is prevented from rising by the thermoelectric element.

Fig. 15 shows a module temperature comparison of the cooling methods when the mode is NOCT and the radiation is rapidly changed. The results show that the average module temperature of the BIPV system using a thermoelectric element is $38.52\left[{ }^{\circ} \mathrm{C}\right]$ and that the average module temperature of the BIPV system using a ventilator is $41.02\left[{ }^{\circ} \mathrm{C}\right]$. Fig. 16 and Fig 17 show a comparison of the module generating value and accumulating generation value based on the cooling method. The generation value when using the thermoelectric element 


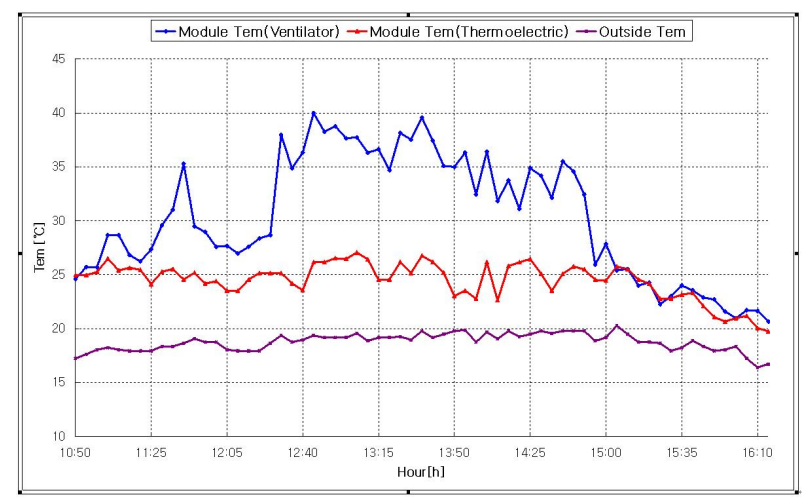

Fig. 9. The comparison to module temperatures by cooling methods (control mode: STC, low level radiation).

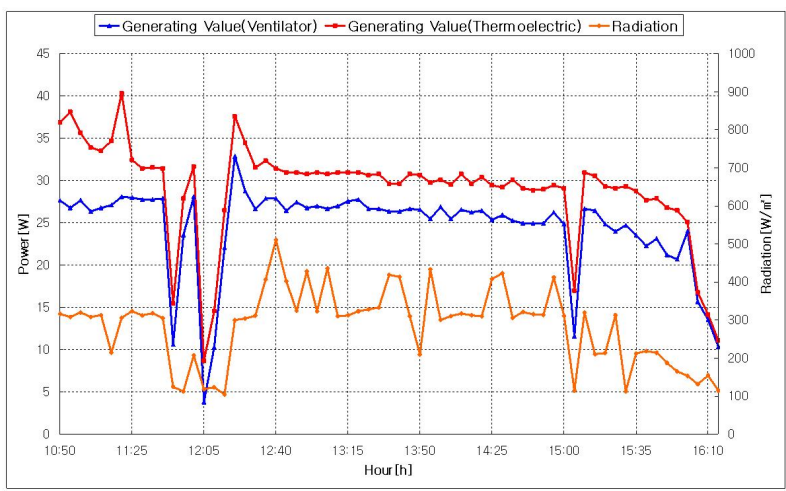

Fig. 10. The comparison to module generating value by cooling methods (control mode: STC, low level radiation).

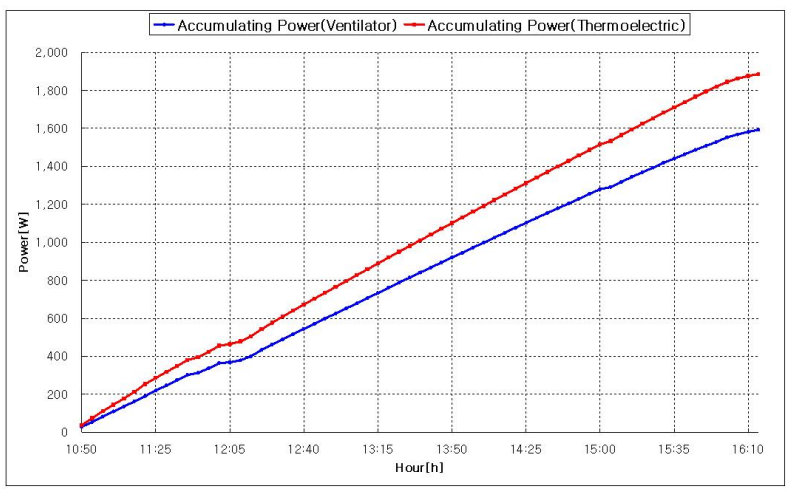

Fig. 11. The comparison to the module accumulated power of cooling methods (control mode: STC, low level radiation).

is higher $28[\mathrm{~W}]$ than when using the ventilator.

Fig. 18 shows a module temperature comparison of the cooling methods when the radiation level is high. The results show that average module temperature of the BIPV system using a thermoelectric element is $45.03\left[{ }^{\circ} \mathrm{C}\right]$ and that the average module temperature of the BIPV system using a ventilator is $59.47\left[{ }^{\circ} \mathrm{C}\right]$. Fig. 19 and Fig 20 show a comparison of the module generating value and accumulating generation value based on the cooling method. The generation value using the thermoelectric element is higher 432.12[W] than when using the ventilator. The air and module temperatures are very high when there are high levels of radiation so if the cooling control system is installed on a BIPV system, the efficiency is

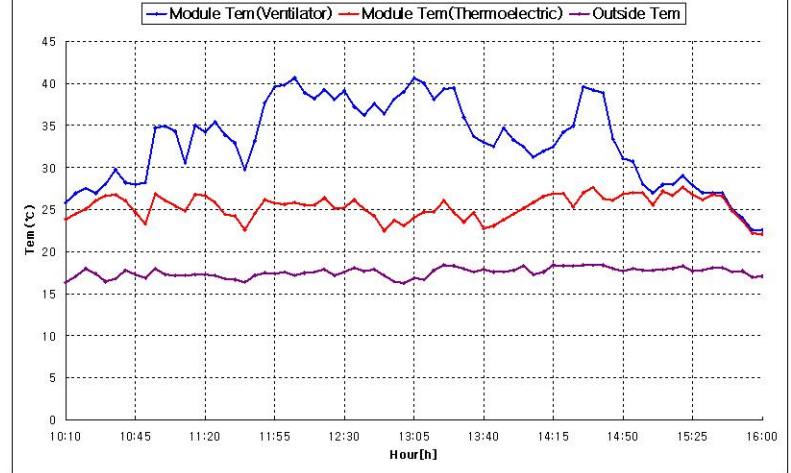

Fig. 12. The comparison to module temperatures by cooling methods (control mode: STC, rapidly changing radiation).

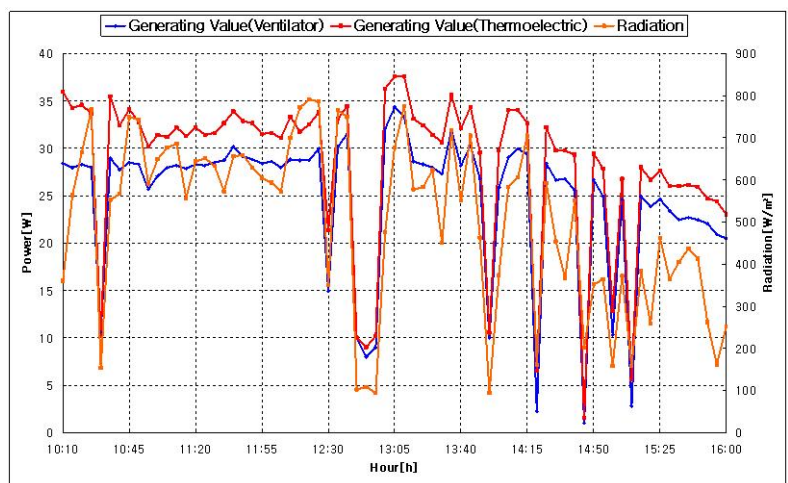

Fig. 13. The comparison to module generating value by cooling methods (control mode: STC, rapidly changing radiation).

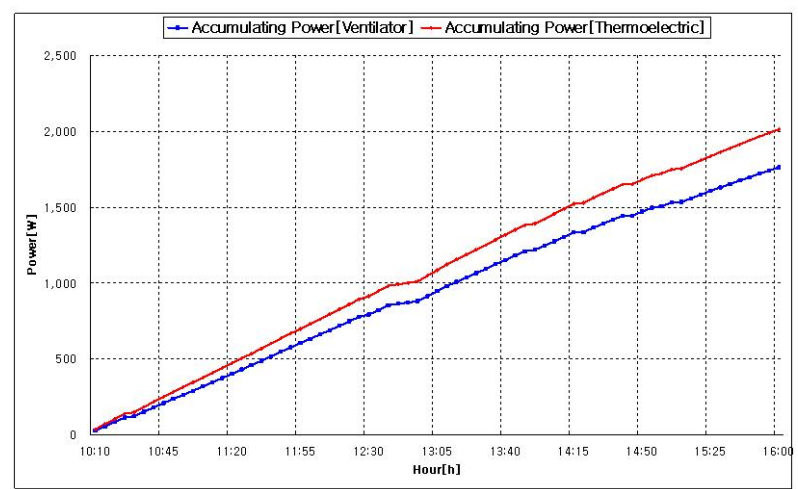

Fig. 14. The comparison to the module accumulated power of cooling methods (control mode: STC, Rapidly changing radiation).

greatly improved. Consequently, the proposed BIPV cooling system, using a thermoelectric element, is able to provide excellent performance.

\section{CONCLUSIONS}

This paper proposes a cooling system using a thermoelectric element for the efficiency improvement of a BIPV module. The BIPV module temperature is higher (about $25 \sim 40^{\circ} \mathrm{C}$ ) than air temperature because it is used on an outer wall which has no air current. This increase in temperature decreases the output power so that the efficiency of the BIPV system is much lower. To solve these problems, this paper proposes novel cooling system using thermoelectric elements. The proposed 


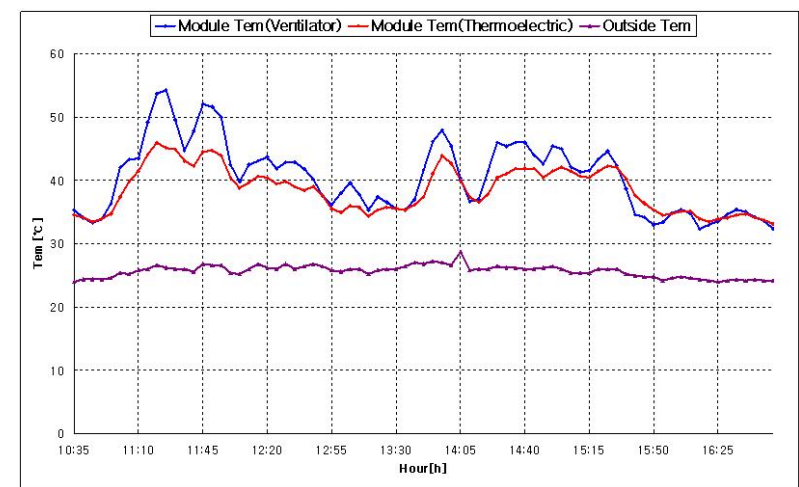

Fig. 15. The comparison to module temperatures by cooling methods (control mode: NOCT, rapidly changing radiation).

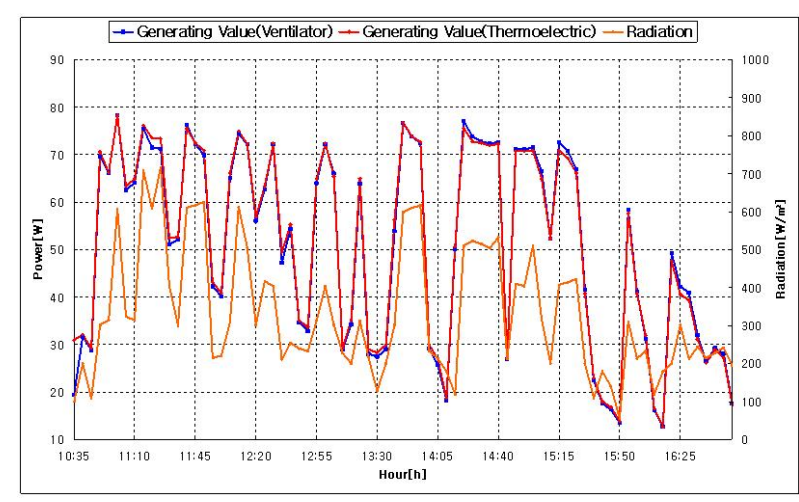

Fig. 16. The comparison to module generating value by cooling methods (control mode: NOCT, rapidly changing radiation).

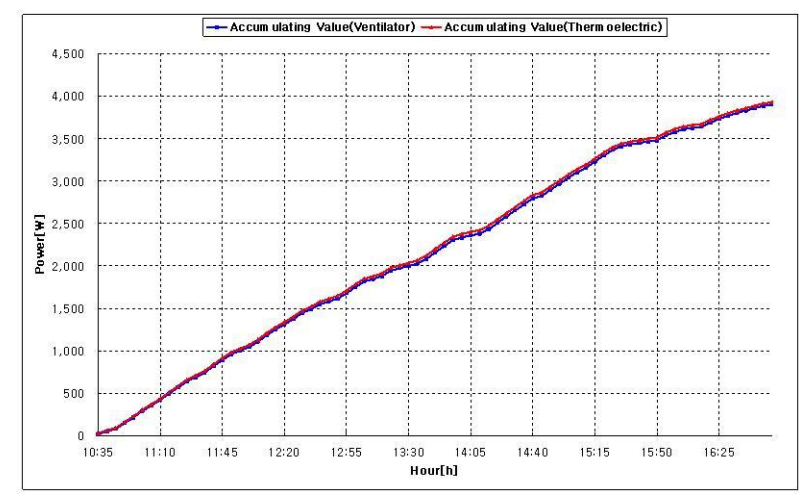

Fig. 17. The comparison to the module accumulated power of cooling methods (control mode: NOCT, Rapidly changing radiation).

method is compared with a conventional ventilation method cooling system. Since the cooling method by a thermoelectric element is operated when the temperature of the BIPV module exceeds a set temperature, the BIPV module is operated within the control value during days with high radiation. Therefore, output power of the BIPV system is higher than it is with the conventional method and the efficiency of BIPV system is increased. In addition, its efficiency can be independently controlled in an outside environment. Therefore, this paper proves the validity of the proposed method which is a BIPV cooling system using a thermoelectric element.

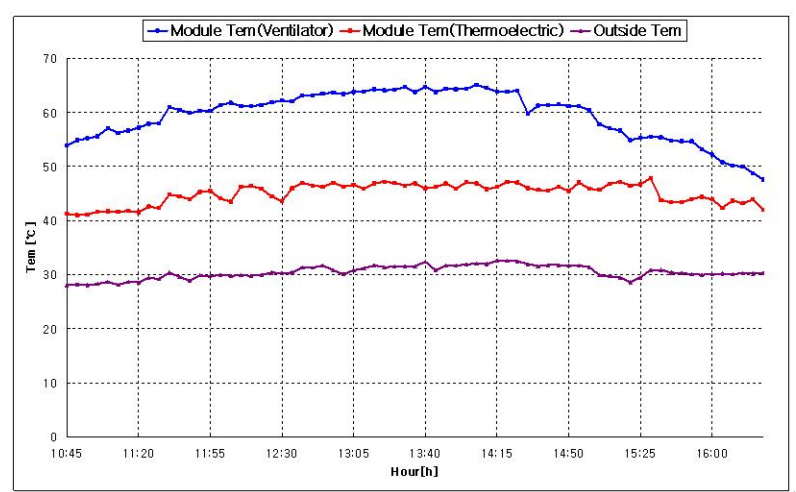

Fig. 18. The comparison to module temperatures by cooling methods (control mode: NOCT, high level radiation).

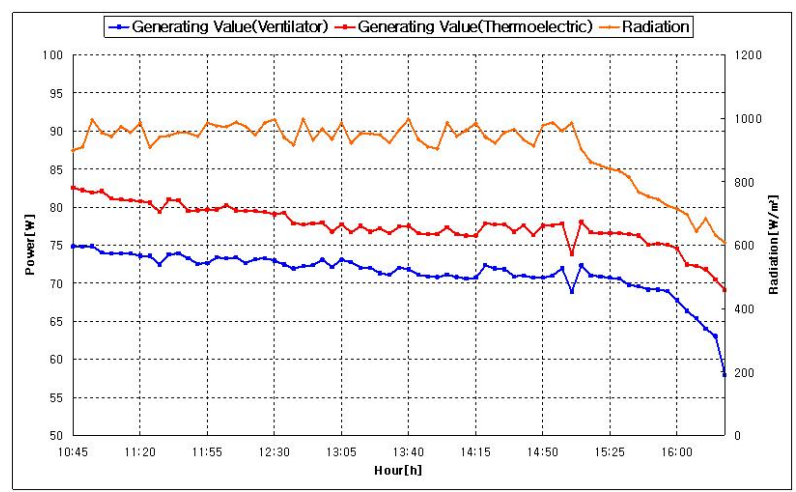

Fig. 19. The comparison to module generating value by cooling methods (control mode: NOCT, high level radiation).

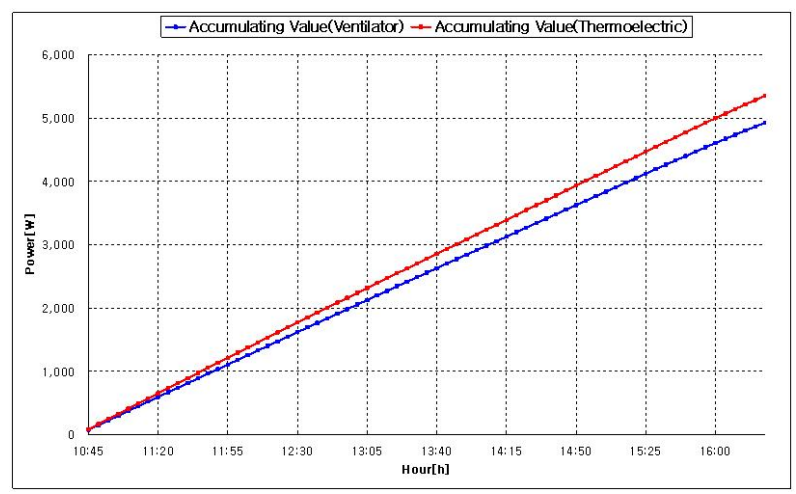

Fig. 20. The comparison to the module accumulated power of cooling methods (control mode: NOCT, high level radiation).

\section{ACKNOWLEDGMENT}

This work was supported by a National Research Foundation of Korea (NRF) grant funded by the Korea government (MEST) (No. 2009-0076397).

\section{REFERENCES}

[1] H. H. R. Ensil, "Maximum point tracking : A cost saving necessity in solar systems," IEEE PESC '90, Vol. 2, pp. 1073-1077, Nov. 1990.

[2] Randall Thomas, Photovoltaics and Architecture, Sponpress, London, p. $14,2001$.

[3] Nkano, H., Sasaki, S., Meda, M., Aiki, K,(1987) "Dual-in-line laser diode module for fiber-opitc transmission up to $4 \mathrm{Gbit} / \mathrm{S}$," J. Lightwave Technol.(USA), Vol. 5, No. 10, pp. 1402-1411, 1987. 
[4] H. S. Kim, J. M. Park, K. B. Jo, H. W. L, "A study on the boost converter for MPPT using micro-controller in PV system," KSES CNF, pp.51-60, 2003.

[5] Geoff Walker, "Evaluating MPPT converter topologies using a matlab PV model," IEAust, Vol. 21, pp. 49-56, 2001.

[6] H. C. Kang, "Characteristic of cooling device using thermoelectric module," Graduate School of Educational Chonnam National University Masters degree paper, 2, 2006.

[7] Hyeong-Ju Noh, Ding-Yun Lee, Ding-Seok Hyun, "An improved MPPT converter with current compensation method for small scaled PVapplications," IEEE IES, Vol. 2, pp. 1113-1118, Nov. 2002.

[8] Jung-Yeol Lim, In-Su Cha, "MPPT for temperature compensation of photovoltaic system with neural networks," ISES'97, pp.275-277, Oct. 1997.

[9] O. Humm et al., op. cit., p.13

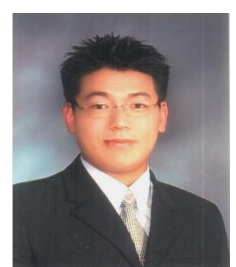

Jung-Sik Choi received his M.Eng in Electrical Control Engineering from Sunchon National University, Korea, in 2005. He is currently working toward his Ph.D. in Electrical Control Engineering at Sunchon National University, Korea. His research interests include fuzzy control, neural networks, motor control and photovoltaic power. His current research focuses on maximum power point tracking control of PV generation.

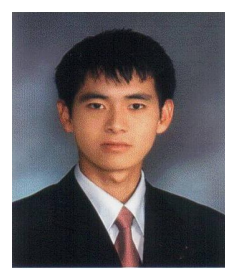

Jae-Sub Ko received his M.Eng in Electrical Control Engineering from Sunchon National University, Korea, in 2005. He is currently working toward his Ph.D. in Electrical Control Engineering at Sunchon National University, Korea. His research interests include fuzzy control, neural networks, motor control and photovoltaic power. His current research focuses on maximum power point tracking control of PV generation.

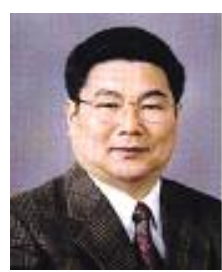

Dong-Hwa Chung received his D.Eng in Electric Engineering from Hanyang University, Korea, in 1987. $\mathrm{He}$ is a professor of Electrical Control Engineering at Sunchon National University, Korea. His research interests include fuzzy control, neural networks, motor control and photovoltaic power. His current research focuses on maximum power point tracking control of PV generation. He has received about twenty awards such as the best paper award and academy research award etc, from the Korean Institute of Electrical Engineers and the Korean Institute of Illuminating and Electrical Installation Engineers etc,. He has authored about 100 papers since 1983. His research interests include power electronics, electric motor control, artificial intelligent control and photovoltaic generation. 